\title{
Thermostability in endoglucanases is fold-specific
}

\author{
Ragothaman M Yennamalli', Andrew J Rader ${ }^{2}$, Jeffrey D Wolt ${ }^{3}$, Taner Z Sen ${ }^{1,4,5^{*}}$
}

\begin{abstract}
Background: Endoglucanases are usually considered to be synergistically involved in the initial stages of cellulose breakdown-an essential step in the bioprocessing of lignocellulosic plant materials into bioethanol. Despite their economic importance, we currently lack a basic understanding of how some endoglucanases can sustain their ability to function at elevated temperatures required for bioprocessing, while others cannot. In this study, we present a detailed comparative analysis of both thermophilic and mesophilic endoglucanases in order to gain insights into origins of thermostability. We analyzed the sequences and structures for sets of endoglucanase proteins drawn from the Carbohydrate-Active enZymes (CAZy) database.

Results: Our results demonstrate that thermophilic endoglucanases and their mesophilic counterparts differ significantly in their amino acid compositions. Strikingly, these compositional differences are specific to protein folds and enzyme families, and lead to differences in intramolecular interactions in a fold-dependent fashion.

Conclusions: Here, we provide fold-specific guidelines to control thermostability in endoglucanases that will aid in making production of biofuels from plant biomass more efficient.
\end{abstract}

\section{Background}

Understanding the molecular basis of thermostability is essential for protein engineering applications where the thermal stability of a protein could potentially be enhanced. An important industrial application is to genetically engineer plants for increased biofuel production. For example, a thermostable endoglucanase from Acidothermus cellulolyticus has been expressed in Zea mays subsp. mays increasing the hydrolysis efficiency for conversion of plant cellulose to ethanol [1]. Using this transgenic modification allows hydrolysis of cellulose fibers to begin a pre-processing step within the plant. Transgenic corn feedstock expressing thermostable endoglucanases is an innovation that simplifies the hydrolysis of cellulose-derived ethanol, and hence lowers the cost of production. Although the details of the exact mechanism through which cellulases act is far from complete, it is usually considered that endoglucanase generates cellulose chain ends, following an attack by cellobiohydrolase for subsequent hydrolysis [2-4].

Although thermophilic enzymes are industrially important, our understanding of the factors responsible

\footnotetext{
* Correspondence: taner@iastate.edu

'Department of Genetics, Development and Cell Biology, lowa State University, Ames, IA 50011, USA

Full list of author information is available at the end of the article
}

for thermostability in these enzymes is still incomplete. Many studies have addressed this question by comparing homologous protein structures from different families as an aggregate set [5-11] or by focusing on differences for a single family [12-14]. These comparative studies typically analyze several factors such as the energy of unfolding, number of VdW contacts per residue, number of hydrogen bonds per residue, or number of residues involved in secondary structure at the protein level [5]. Often, these studies have sought to identify any detectable relationship between amino acid composition and thermostability. One of the earlier comparative studies with 18 different families of proteins observed that Arg and Tyr are significantly higher in thermophiles, while Cys and Ser are significantly lower in thermophilic proteins [7]. In a study by Sarai's group, the following factors were argued to impart thermostability: Gibbs free energy change of hydration, long-range non-bonded energy, $\beta$-strand tendency and average long-range contacts [11]. However, rather than identifying the structural or sequence-based rules governing increased thermostability these comparisons have instead only suggested many physical or structural features that may impart thermostability, including preferences of certain amino acids [7], increased hydrophobicity [8], or even a single amino acid mutation [14]. By
C Biomed Central

(c) 2011 Yennamalli et al; licensee BioMed Central Ltd. This is an Open Access article distributed under the terms of the Creative Commons Attribution License (http://creativecommons.org/licenses/by/2.0), which permits unrestricted use, distribution, and reproduction in any medium, provided the original work is properly cited. 
extending the comparison to many different pairs of proteins from two organisms (one thermophilic and one mesophilic) factors such as increase in compactness and sequence dependent strong interactions have been identified as two physical mechanisms underlying thermostability [5].

Previously reported studies $[5,10,15,16]$ involving comparison of thermophilic and mesophilic organism's proteome have led to the conclusion that positively charged residues play an important role in imparting thermophilicity. Berezovsky and Shakhnovich [5] concluded that the strategy of organism's adaptation in a thermophilic environment depends on the "evolutionary history" and "sequence-based" mechanism.

In another approach to the proteome level study, the entire proteome of specific organisms were homology modelled from the PDB database and both sequential and structural comparisons were made between thermophiles and mesophiles. Berezovsky et al [15] used two independently different datasets (the Mintz dataset consisting of 2907 protein structures and the Bordner dataset consisting of 435 protein structures). These authors considered a temperature cutoff of $50^{\circ} \mathrm{C}$ for classifying thermophiles or mesophiles and concluded that positively charged amino acids play a crucial role in thermophilic proteins by stabilizing the interface and overall protein structures. Chakravarty and Varadarajan [16] used 21 mesophilic (900 protein structures) and 9 thermophilic (300 protein structures) organisms as the dataset and a temperature cutoff of $37^{\circ} \mathrm{C}$ to differentiate thermophiles from mesophiles. Their results showed that Val and Glu are significantly higher in thermophiles and are also solvent exposed. At the same time, Gln, Asn, Ser, Thr, and His are significantly lower in thermophiles. Comparison of intramolecular interactions showed that cation- $\pi$ interactions are highly significant in imparting thermophilicity. Similarly, Glyakina et al [10] showed that positively charged residues (Lys, Arg and Glu) on the solvent accessible surface are more significant in thermophiles than in mesophiles.

Because the features that cause thermostability for one protein family are not significant for other families of thermophilic proteins, many studies have focused on thermostabilizing features within a single protein family $[12,14,17,18]$. In the case of the $(\alpha / \beta)_{8}$ fold in glycosyl hydrolases (GHs), for example, it was reported that a reduction in the number of Gly residues in thermophilic proteins led to greater stability at higher temperatures [12]. However, this study had two shortcomings: the criteria to select a data set of 29 proteins was solely based on higher crystallographic resolution, but not on lower sequence identities, which can bias the results substantially. And among the 29 structures used, there were only three endoglucanase structures (E.C 3.2.1.4) in the thermophilic set whereas none from the same enzyme class in the mesophilic set. Therefore, the study analyzed the lack of Gly preference in thermophilic glycosyl hydrolase enzymes, rather than endoglucanases specifically. In contrast, here we focus specifically on endoglucanases (E.C. 3.2.1.4) that share no more than $70 \%$ sequence identity.

From structural comparisons of proteins from a single fold, Sandgren et al experimentally found that a single amino acid mutation of alanine to valine was responsible for thermal stability among the GH12 family of endoglucanases [14]. Although cases where a single residue change imparts increased stability are quite rare, similar examples can be found in a cold shock protein where two residues confer thermostability [19].

The overall inability to identify common trends for thermostability among many different protein families has caused some to speculate that no single rule defines protein thermostability and the factors determining thermostability for one fold or family of proteins may never be universally applicable [12]. More likely, these comparisons between homologous proteins are complicated by the underlying, unknown relationships between protein sequence, structure, and function. For example, several studies implicated intrinsic disorder as a factor in thermostability at low temperatures, where an increase in temperature induces partial, reversible folding of the protein $[20,21]$. With the recent hypothesis that psychrophilic (cold-loving) proteins are intrinsically disordered [22], this complex relationship is far from resolved. Another issue to consider is the evolution of folds. The emergence of folds within an enzyme family is likely due to convergent evolution of the different protein structures adapting to the same substrate (cellulose for endoglucanases) at different evolutionary periods. Convergent evolution of distinct folds adapting to perform the same function and mechanism is well documented in pathogenic virulence factors [23], lectins [24], toxins [25], receptors [26], and kinases [27]. Hence, the question of the fold effect on thermostability for a protein enzyme family addresses whether convergent evolution for that family adopted different or similar factors to impart thermostability.

Here we investigate how the evolution-driven mechanisms imparting thermostability may vary for different folds. We look at the sequence- and structure-based factors that can contribute to thermostability for the family of endoglucanase proteins across and within three distinct folds, namely the $(\alpha / \beta)_{8}$ fold, $\beta$-jelly roll fold and the $(\alpha / \alpha)_{6}$ fold. We specifically concentrate on 1,4- $\beta$-Dglucanases or endoglucanases, which belong to the broader family of enzymes known as glycosyl hydrolases, extracted from bacterial and fungal sources. Glycosyl hydrolases are enzymes that hydrolyze complex 
carbohydrate moieties and are comprised of cellulase, xylanase, pectinases, $\beta$-glucanase, exocellulase, mananase etc [28]. They are widely used in a wide range of industrial applications, such as juice and wine industries for clarification of beverages; feed industries for increasing the digestibility of the feed; paper and pulp industries for pulp bleaching process; textile industries for selective modification of cellulose fibers (depilling); and in reproducing the stonewashing effect on jeans [29].

In the last few years, cellulases have been used in the conversion of biomass to fermentable sugars for ethanol production. Currently they are extracted from microbial sources leading to increased production costs [30]. Considerable efforts are being undertaken towards improved yield and reduced costs of bioethanol production [31]. Even though they share the same structural fold and catalytic mechanism, our knowledge is limited as to why certain endoglucanases are thermophilic. Understanding this limitation is crucial for enhanced utilization of thermophilic endoglucanases for conversion of biomass to bioethanol. Although both protein folds and protein functions play a role in contributing to thermostability, our hypothesis is that protein folds rather than protein families dominate in determining which specific factors are responsible for protein thermostability.

\section{Results and Discussion}

\section{Fold diversity in endoglucanases}

Endoglucanases (E.C 3.2.1.4) have three distinct structure folds: the $(\alpha / \beta)_{8}$ fold, $\beta$-jelly roll fold and the $(\alpha / \alpha)$ ${ }_{6}$ fold (Figure 1).

\section{$(\alpha / \beta)_{8}$ fold (GH5 and GH44 families)}

This fold has an alternating pattern of eight $\alpha$ and $\beta$ subunits in a single domain, such that the eight parallel $\beta$ strands on the inside are protected by eight $\alpha$ helices on the outside (Figure 1A). Often referred to as a TIM barrel because it was first discovered in the triosephosphate isomerase (TIM) enzyme, this extremely common fold has been reported to display the highest diversity of enzymatic functions [32]. Endoglucanases in glycosyl hydrolases families 5 (GH 5) and 44 (GH 44) share this fold.

\section{$\beta$-jelly roll fold (GH7 and GH12 families)}

This fold consists of $15 \beta$-strands in two twisted antiparallel $\beta$-sheets, named $A$ and $B$, that pack against each another (Figure 1B). $\beta$-sheet $A$ contains six antiparallel $\beta$-strands forming the back, convex surface while $\beta$-sheet $B$ contains nine anti-parallel $\beta$-strands arranged to form the front, concave binding surface [29]. Additionally two $\alpha$-helices pack against the back side of $\beta$-sheet $B$.

\section{$(\alpha / \alpha)_{6}$ fold (GH8, GH48 and GH9 families)}

The substrate binding cleft in this fold has a tunnel shape formed at the $\mathrm{N}$-termini of six central, parallel $\alpha$-helices (Figure 1C). These six helices are surrounded by six external $\alpha$-helices. Unlike the $(\alpha / \beta)_{8}$ and $\beta$-jelly roll folds, the $(\alpha / \alpha)_{6}$ fold utilizes the inverting mechanism for hydrolyzing glycosidic bonds (see below) [33].

\section{Fold-dependent cellulose hydrolysis in endoglucanases}

Cellulose is a linear homo-polysaccharide made up of glucose units that are linked by $\beta-1,4$-glycosidic bonds. There are two ends of the polymer: a reducing end, where the terminating anomeric carbon is not linked to another glucose unit, and a non-reducing end. Upon synthesis, cellulose forms as microfibrils that are strengthened by hydrogen, hydrophobic and van der Waals interactions, making it more resistant to hydrolysis than starch, which is made up of $\alpha-1,4$-glycosidic bonds. Two main different catalytic mechanisms are employed by the glycosyl hydrolases for hydrolysis of glycosidic bonds: the retaining and the inverting mechanisms [29].

\section{Retaining mechanism}

In this mechanism (Figure 1D), the stereometric configuration of the anomeric carbon is retained in the $\beta$ configuration after hydrolysis. A pair of Glu amino acids, separated by $5.5 \AA$, act as the catalytic residues: one as a nucleophile and the other an acid-base donor. The first step in this double displacement mechanism is glycosylation, where one of the catalytic residue's carboxylic group induces acid-catalyzed leaving group departure simultaneous to a nucleophilic attack on the anomeric carbon to form a glycosyl-enzyme intermediate by the second catalytic residue's carboxylic group. In the second step, a water molecule acts as a nucleophile and the first residue's carboxylic group acts as a base. Once deprotonated, the water molecule is an activated nucleophile that then hydrolyzes the glycosyl-enzyme intermediate leading to a break in the polymer. The $(\alpha / \beta)_{8}$ (GH5 and GH44 families) and $\beta$-jelly roll (GH7 and GH12 families) folds use the retaining mechanism.

\section{Inverting mechanism}

In this mechanism (Figure 1E), the configuration of the anomeric carbon is inverted; i.e., hydrolysis of $\beta$-glycosidic bond leads to $\alpha$-configuration of carbon and vice versa. The details of this enzymatic mechanism are still not completely known. Glu-Glu pairs usually act as acid-based donors, but recent studies also suggest that Asp may act as the base donor in inverting cellulases [34,35]. Alzari's work [35] suggests specifically Asp as the probable catalytic base in the family GH8. Therefore a pair of Glu-Glu or in some cases Glu-Asp amino acid pairs, separated by $6.5 \AA$ to $9.5 \AA$, may act as acid-base donors and a water molecule acts as a nucleophile. Utilizing the water molecule on the opposite side of the sugar ring to stabilize the transition, these residues catalyze the glycosylation or deglycosylation in one step. 


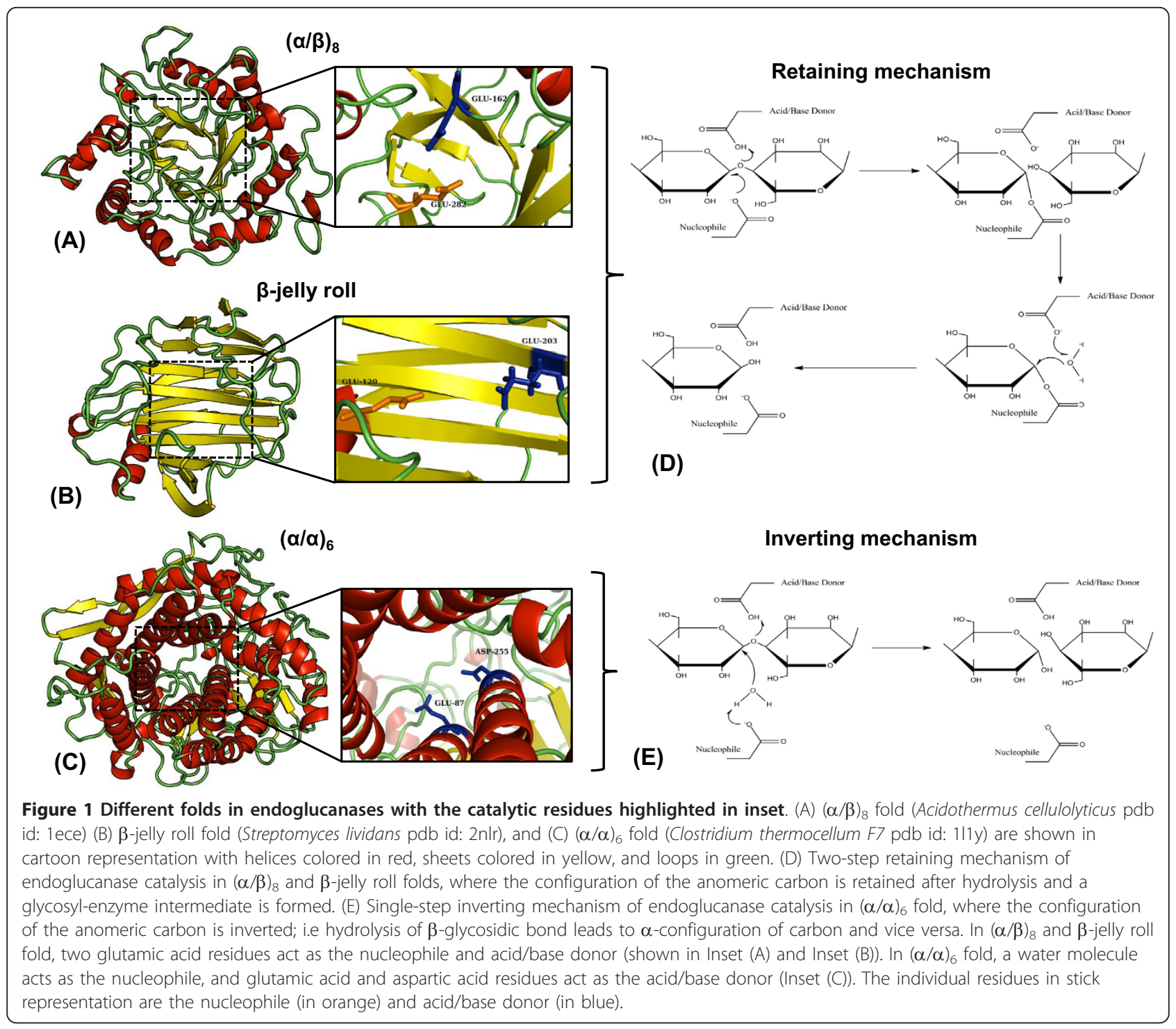

Unlike the retaining mechanism, this mechanism does not involve the glycosyl-enzyme intermediate. The $(\alpha / \alpha)$ ${ }_{6}$ fold (GH8, GH48 and GH9 families) uses the inverting mechanism for cellulose hydrolysis.

\section{Amino Acid Composition and Intramolecular Interactions}

It has long been suggested that in order to function at higher temperatures, thermophilic proteins contain amino acids that contribute to stronger interactions, which stabilize the structure as compared to mesophiles. Such amino acids form salt-bridges [36], disulfide bonds [37] or cause greater core hydrophobicity [8]. In order to investigate whether this holds true for endoglucanases, we examined the statistical significance of different amino acid compositions and various intramolecular features between mesophilic and thermophilic proteins.
In order to identify the different roles that catalytic mechanism or overall structural fold might play in contributing to these differences, we performed the comparison between thermophilic and mesophilic proteins for each of the following datasets: (A) the dataset comprising all endoglucanases as a enzyme group; (B) two datasets representing each of the two catalytic mechanisms; and $(C)$ three datasets representing the three distinct folds separately. In each of the datasets, the proteins were categorized as thermophilic or mesophilic. Table 1 lists the thermophilic and mesophilic endoglucanases in the three distinct folds.

As described in the Methods section (see below), to identify the significant amino acids (Figure 2 and Figure 3) that make a contribution towards stabilizing the protein structure, intramolecular interactions were calculated. After normalizing with respect the protein 
Table 1 Protein sets of Thermophilic and Mesophilic endoglucanases

\begin{tabular}{|c|c|c|c|c|c|c|c|c|c|}
\hline & $(\alpha / \beta)_{8}$ & fold & & $\beta$-jelly & roll fold & & $(\alpha / \alpha)_{6} f$ & & \\
\hline & GH5 and GH & 44 famili & & GH7 and $\mathrm{C}$ & $\mathrm{H} 12$ fami & & GH8, GH48, and & GH9 fami & \\
\hline & Organism & PDB id & Length & Organism & PDB id & Length & Organism & PDB id & Length \\
\hline & Pyrococcus horikoshii & 2zum & 458 & $\begin{array}{c}\text { Humicola } \\
\text { insolens }\end{array}$ & 10jj & 402 & $\begin{array}{c}\text { Clostridium } \\
\text { thermocellum NCIB }\end{array}$ & $1 \mathrm{kwf}$ & 363 \\
\hline & $\begin{array}{l}\text { Acidothermus } \\
\text { cellulolyticus }\end{array}$ & 1ece & 358 & Humicola grisea & $10 \mathrm{lr}$ & 224 & $\begin{array}{l}\text { Clostridium } \\
\text { thermocellum }\end{array}$ & $1 \mathrm{clc}$ & 639 \\
\hline $\begin{array}{l}\text { Thermophilic } \\
\text { Endoglucanases }\end{array}$ & $\begin{array}{l}\text { Clostridium } \\
\text { cellulolyticum }\end{array}$ & 1edg & 380 & $\begin{array}{c}\text { Rhodotermus } \\
\text { marinus }\end{array}$ & $2 b w 8$ & 227 & $\begin{array}{l}\text { Acyclobacillus } \\
\text { acidocaldarius }\end{array}$ & $3 g z k$ & 537 \\
\hline & $\begin{array}{l}\text { Clostridium } \\
\text { thermocellum }\end{array}$ & 1cec & 343 & $\begin{array}{l}\text { Fusarium } \\
\text { oxysporum }\end{array}$ & 3ovw & 411 & $\begin{array}{c}\text { Clostridium } \\
\text { thermocellum F7 }\end{array}$ & $111 y$ & 678 \\
\hline & Bacillus sp.kas-635 & $1 \mathrm{~g} 0 \mathrm{c}$ & 364 & & & & Thermobifida fusca & $1 \mathrm{tf} 4$ & 605 \\
\hline & $\begin{array}{c}\text { Thermoascus } \\
\text { auranticus }\end{array}$ & $1 \mathrm{~h} 1 \mathrm{n}$ & 305 & & & & & & \\
\hline & $\begin{array}{l}\text { Uncultured } \\
\text { bacterium }\end{array}$ & 3ii & 535 & & & & & & \\
\hline & $\begin{array}{l}\text { Clostridium } \\
\text { thermocellum }\end{array}$ & $2 \mathrm{e} 4 \mathrm{t}$ & 509 & & & & & & \\
\hline & Prevotella bryantii & 3155 & 353 & $\begin{array}{c}\text { Streptomyces } \\
\text { lividans }\end{array}$ & $2 n \mid r$ & 234 & Gluconacebacter xylinus & $1 w Z z$ & 334 \\
\hline $\begin{array}{c}\text { Mesophilic } \\
\text { Endoglucanases }\end{array}$ & $\begin{array}{c}\text { Bacillus } \\
\text { agaradhaerens }\end{array}$ & $7 a 3 h$ & 303 & $\begin{array}{c}\text { Hypocrea } \\
\text { jecorina }\end{array}$ & $10 a 2$ & 218 & $\begin{array}{l}\text { Nasutitermes } \\
\text { takasagoensis }\end{array}$ & $1 \mathrm{ks} 8$ & 433 \\
\hline & $\begin{array}{c}\text { Erwinia } \\
\text { chrysanthemi }\end{array}$ & legz & 291 & $\begin{array}{c}\text { Bacillus } \\
\text { licheniformis }\end{array}$ & 2jen & 261 & $\begin{array}{l}\text { Clostridium } \\
\text { cellulolyticum }\end{array}$ & $1 \mathrm{~g} 87$ & 614 \\
\hline & $\begin{array}{c}\text { Clostridium } \\
\text { acetobutylicum }\end{array}$ & $3 i k 2$ & 512 & Aspergillus niger & $1 \mathrm{ks} 5$ & 223 & $\begin{array}{l}\text { Clostridium } \\
\text { cellulolyticum }\end{array}$ & 1 ia6 & 441 \\
\hline & & & & & & & $\begin{array}{l}\text { Clostridium } \\
\text { cellulolyticum }\end{array}$ & $1 \mathrm{~g} 9 \mathrm{~g}$ & 629 \\
\hline
\end{tabular}

A subset of proteins with less than or equal to $70 \%$ sequence identity was created as described in the Methods section. A protein is considered thermophilic if the source organism's optimum growth temperature is above $40^{\circ} \mathrm{C}$. GH stands for glycosyl hydrolase.

length, t-test was performed to identify statistical significance (Figure 3; please see Additional file 1 for detailed quantitative results).

In the larger dataset representing the entire endoglucanase enzyme group, we observed that amino acids Arg and Met are statistically significant among thermophiles, whereas Gln and Ser are statistically significant among mesophiles (Figure 2A and Figure 3). It was previously reported that thermophilic glycosyl hydrolases are significantly missing Gly residues compared to their mesophilic counterparts [8], but we did not observe this negative preference in the case of endoglucanase thermophiles. This difference might be attributed to the fact that endoglucanases form only a small part of the glycosyl hydrolases data set used in the previous study.

We also compared significant intramolecular interactions in thermophiles and mesophiles. For the thermophiles, only ionic interactions were significant, whereas for mesophiles, no intramolecular interactions were significantly different from thermophiles.

We also analyzed the effect of catalytic mechanism on the amino acid distribution and intramolecular interactions. In the retaining mechanism $\left((\alpha / \beta)_{8}\right.$ and $\beta$-jelly roll folds) amino acids Leu, Met, Pro, and Arg were significant among thermophiles, whereas Ser and Val were significant among mesophiles (Figure $2 \mathrm{~B}$ and Figure 3). For the same mechanism, the MC-SC hydrogen bond interactions were significant among thermophiles. In the inverting mechanism $\left((\alpha / \alpha)_{6}\right.$ fold $)$ amino acids Glu, Val were significant among thermophiles, whereas only Gln was significant among mesophiles (Figure 2E and Figure 3 ). However, none of the intramolecular interactions were significant. Strikingly, the significant amino acids and intramolecular interactions are different for the catalytic mechanisms than for endoglucanases as an enzyme group. Another interesting observation is that the significant amino acids and intramolecular interactions for the retaining mechanism are different than those of the individual folds that make up that mechanism. This result strengthens the idea that the analyses of folds provide more informative and detailed understanding of thermostability than a larger set made of many folds.

It is noteworthy that overlaps of amino acid preferences exist if we compare different folds of the endoglucanases. For example, between $(\alpha / \beta)_{8}$ and $\beta$-jelly roll folds, Arg and Leu are significantly higher in thermophiles than in 


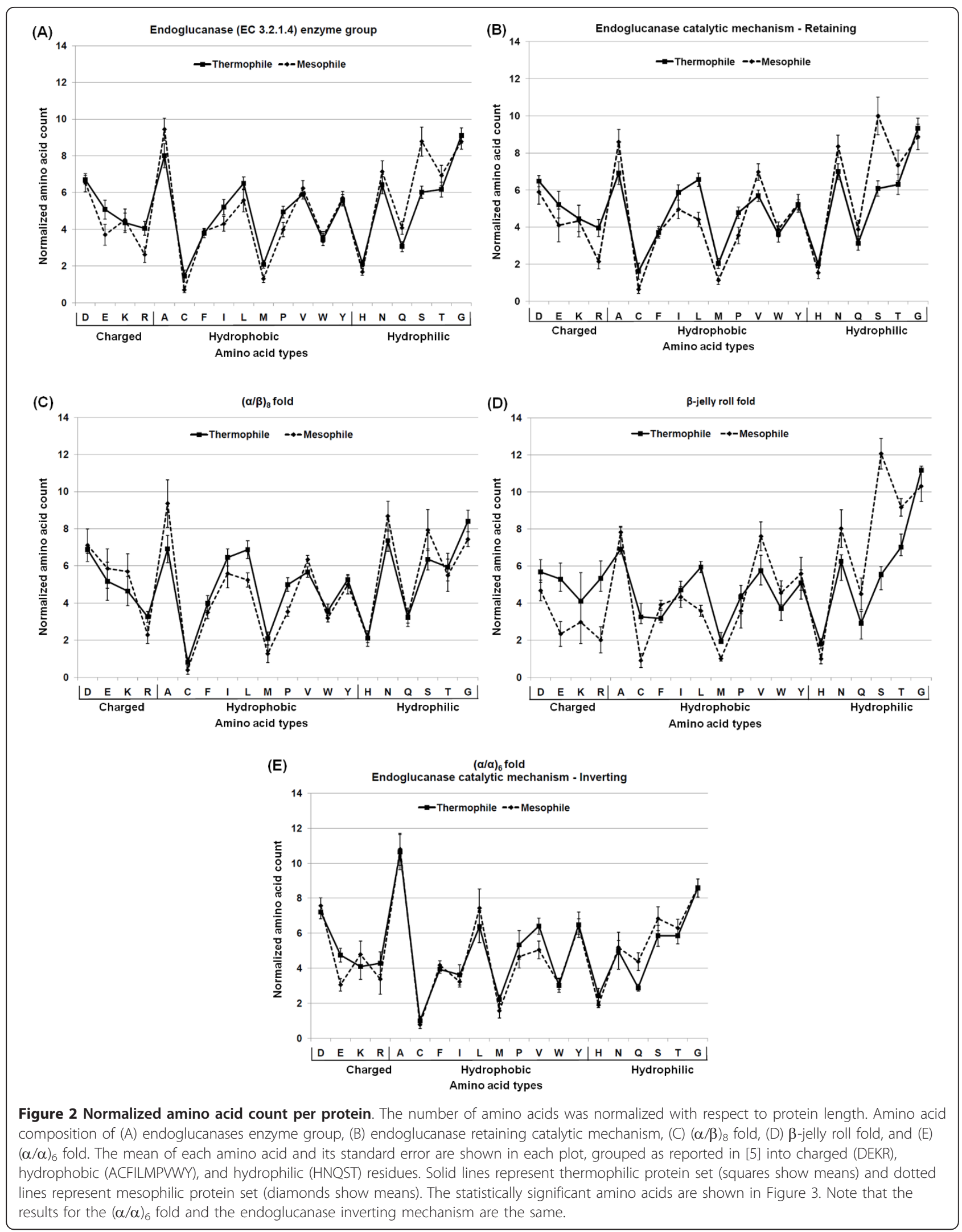




\begin{tabular}{|c|c|c|c|c|c|c|c|}
\hline & & \multirow{2}{*}{ 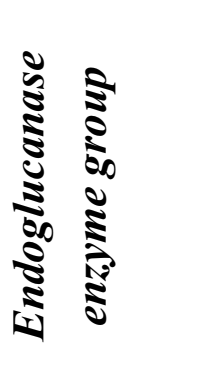 } & \multicolumn{2}{|c|}{$\begin{array}{c}\text { Catalytic } \\
\text { Mechanism }\end{array}$} & \multicolumn{3}{|c|}{ Folds } \\
\hline & & & $\begin{array}{c}\text { Retaining } \\
(\alpha / \beta)_{8} \text { and } \\
\beta \text {-jelly roll } \\
\text { folds }\end{array}$ & $\begin{array}{c}\text { Inverting } \\
(\alpha / \alpha)_{6} \\
\text { fold }\end{array}$ & $\underbrace{\infty}$ & 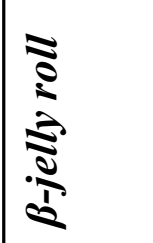 & $\frac{8}{8}$ \\
\hline \multirow{2}{*}{ } & In Thermophile & Met, Arg & $\begin{array}{l}\text { Leu, Met, } \\
\text { Pro, Arg }\end{array}$ & Glu, Val & $\begin{array}{l}\text { Arg, } \\
\text { Leu, } \\
\text { Pro }\end{array}$ & $\begin{array}{c}\text { Glu, } \\
\text { Arg, } \\
\text { Cys, } \\
\text { Leu, } \\
\text { His }\end{array}$ & $\begin{array}{l}\text { Glu, } \\
\text { Val }\end{array}$ \\
\hline & In Mesophile & Gln, Ser & Ser, Val & Gln & - & $\begin{array}{l}\text { Ser, } \\
\text { Thr }\end{array}$ & Gln \\
\hline \multirow{9}{*}{ 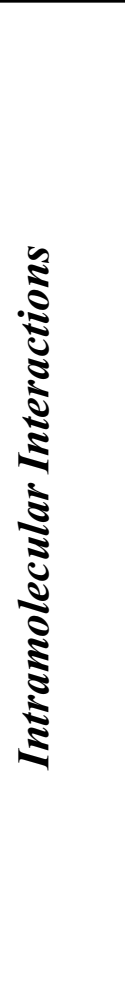 } & $\begin{array}{r}\text { main chain-main- } \\
\text { chain }(\mathrm{MC}-\mathrm{MC})\end{array}$ & & & & & $3.1 \times 10^{-2}$ & \\
\hline & $\begin{array}{r}\text { main chain-side } \\
\text { chain }(\mathrm{MC}-\mathrm{SC})\end{array}$ & & $2.5 \times 10^{-2}$ & & & & \\
\hline & $\begin{array}{l}\text { side chain-side } \\
\text { chain }(\mathrm{SC}-\mathrm{SC})\end{array}$ & & & & & & \\
\hline & hydrophobic & & & & & & \\
\hline & ionic & $4.3 \times 10^{-2}$ & & & & $7.8 \times 10^{-3}$ & \\
\hline & disulphide bonds & & & & & & \\
\hline & aromatic & & & & & & \\
\hline & aromatic-sulfur & & & & & $3.9 \times 10^{-2}$ & \\
\hline & cation- $\pi$ & & $4.2 \times 10^{-2}$ & & & & \\
\hline $\begin{array}{l}\text { jure } 3 \mathrm{~s} \\
\text { ey are sh } \\
\text { iir mesop } \\
\text { te that } t\end{array}$ & $\begin{array}{l}\text { cally significant amino a } \\
\text { thermophilic endoglucan } \\
\text { ounterparts ( } p \text {-value }<5.0 \\
\text { lts for inverting mechanis }\end{array}$ & $\begin{array}{l}\text { s and intramol } \\
\text { s as an enzyme } \\
\left.0^{-2}\right) \text {. The statistic } \\
\text { nd on }(\alpha / \alpha)_{6} \text { fo }\end{array}$ & $\begin{array}{l}\text { ficant intran } \\
\text { same. }\end{array}$ & $\begin{array}{l}\text { en therm } \\
\text { on mechan } \\
\text { ar interacti }\end{array}$ & $\begin{array}{l}\text { and } \\
\text { id witt } \\
\text { thern }\end{array}$ & $\begin{array}{l}\text { philic en } \\
\text { ch fold, a } \\
\text { les are sh }\end{array}$ & oared tc \\
\hline
\end{tabular}


mesophiles (Figure 2C and 2D). Similarly, between $\beta$-jelly roll and $(\alpha / \alpha)_{6}$ folds, Glu is significantly higher in thermophiles than in mesophiles (Figure 2D and 2E). Similarities in amino acid preferences within an enzyme class are usually assumed in many protein analyses. These class-specific similarities are actually the basis of those analyses that involve protein properties averaged over many enzyme classes and families. We show here that although similarities exist among the proteins forming an enzyme class, strong fold-specific differences are also present that need to be considered to understand the origin of thermostability.

\section{Secondary Structure and Solvent Exposure Preference}

After identifying a subset of amino acids as statistically significant, we investigated if these amino acids displayed a preference for secondary structure state or solvent exposure.

\section{$(\alpha / \beta)_{8}$ fold}

In the GH5 and GH44 families, Arg, Leu, and Pro were statistically more significant in thermophiles than in mesophiles, while none of the amino acids were statistically significant among mesophiles (Figure 2C, Figure 3 and Additional file 2). Pro is significantly absent in the $\beta$-sheets of the mesophiles whereas prominently present in the $\beta$-sheets in thermophiles (Figure 4, Additional file 3 and Additional file 4). Similarly, Pro in thermophiles is significant in the intermediate class of relative surface accessibility (Figure 4 ).

\section{$\beta$-jelly roll fold}

In GH7 and GH12 families, Glu, Arg, Cys, Leu, and His were statistically significant in thermophiles. The amino acids Ser and Thr were statistically significant in mesophiles (Figure 2D, Figure 3 and Additional file 2). Among the thermophiles Glu was significant in helices but absent in mesophiles (Figure 4, Additional file 3 and Additional file 4). Also all the Cys are significant in the buried class. His is extremely significant in the intermediate class in thermophiles than in mesophiles (Figure 4). Leu is highly significant in the exposed class for thermophiles, as no Leu is exposed in mesophiles.

\section{$(\alpha / \alpha)_{6}$ fold}

Similarly, in GH8, GH48, and GH9 families, Glu and Val were statistically significant in thermophiles and Gln

\begin{tabular}{|c|c|c|c|c|c|c|c|}
\hline \multirow{2}{*}{ Fold } & \multirow{2}{*}{$\begin{array}{l}\text { Significant } \\
\text { Amino Acid }\end{array}$} & \multicolumn{3}{|c|}{ Secondary structure } & \multicolumn{3}{|c|}{ Relative Surface Accessibility } \\
\hline & & Helix & Sheet & Loop & Buried & Intermediate & Exposed \\
\hline \multirow{3}{*}{$(\alpha / \beta)_{8}$ fold } & Arg & & & & & & \\
\hline & Leu & & & & & & \\
\hline & Pro & & $1.0 \times 10^{-2}$ & & & $5.0 \times 10^{-2}$ & \\
\hline \multirow{5}{*}{$\beta$-jelly roll fold } & Glu & $4.6 \times 10^{-2}$ & & & & & \\
\hline & Arg & & & & & & \\
\hline & Cys & & & & $3.6 \times 10^{-2}$ & & \\
\hline & Leu & & & & & & $4.7 \times 10^{-3}$ \\
\hline & His & & & & & $5.0 \times 10^{-3}$ & \\
\hline \multirow{2}{*}{$(\alpha / \alpha)_{6}$ fold } & Glu & & & & & & \\
\hline & Val & & & & & & \\
\hline \multicolumn{8}{|c|}{$\begin{array}{l}\text { Figure } 4 \text { The p-values for secondary structure and relative surface accessibility preferences for the statistically significant amino acid } \\
\text { in thermophilic proteins among the three folds. The eight state classification of DSSP was reduced into three states (Helix, Sheet, and Loop) } \\
\text { as described in the text. The amino acids are classified into three classes according to relative surface accessibility: buried, if less than 9\%; } \\
\text { intermediate, if between } 9-36 \% \text {; and exposed, if more than } 36 \% \text { [43]. The statistically significant secondary structure and solvent exposure } \\
\text { preferences for amino acids are bolded and underlined and p-values are provided. Our analysis showed that the significant amino acids in } \\
\text { mesophilic proteins do not show statistically significant preferences for secondary structure or solvent exposure. }\end{array}$} \\
\hline
\end{tabular}




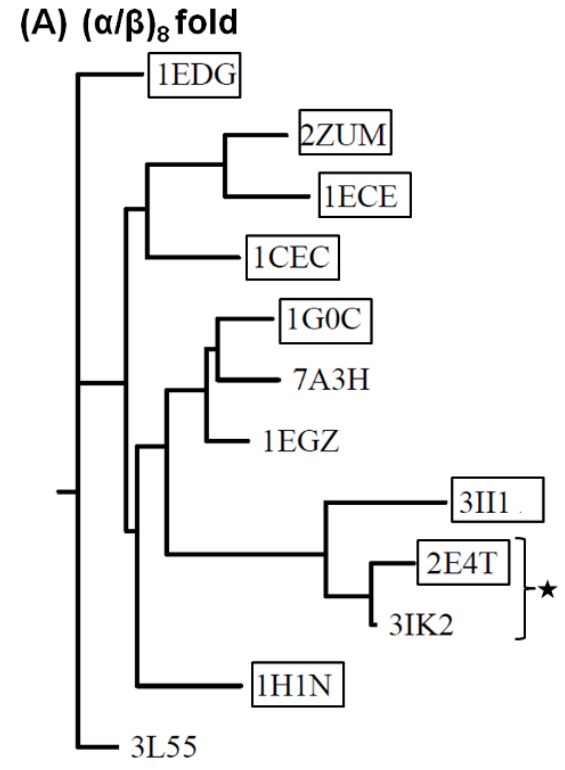

(B) $\beta$-jelly roll fold

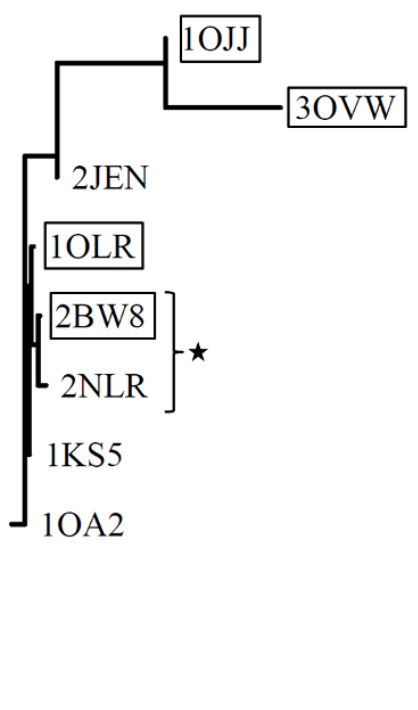

(C) $(\alpha / \alpha)_{6}$ fold

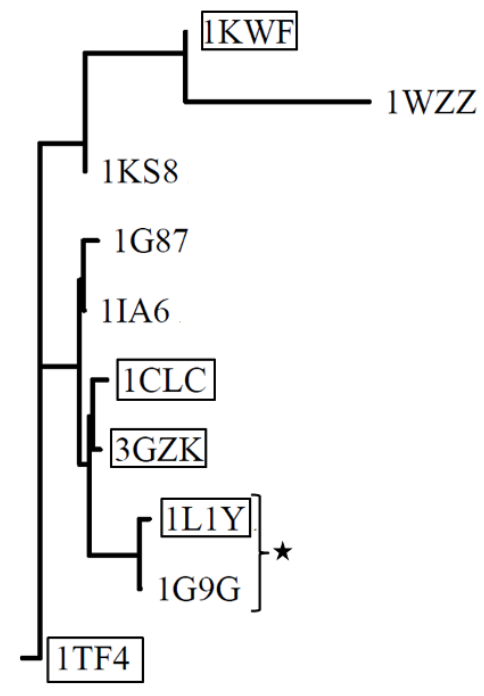

(D)
2E4T:A $181 / 188$
PALWSHTHARTHPDNVTAKELIEKSVALSKAVKKVDPYAE IFGPALYGFAAYETLQSAPD
3IK2:A $181 / 182$ PSLWPSTHA $L$ IHPDKTKCSEVLDKDTQLAQVVKKIDPAAETFGPALFGFSAFNDFNSSPD
2E $4 \mathrm{~T}: \mathrm{A} \quad 241 / 248$
WGTEGEGYRNFIDYYLDKMKKASDEEGKRLLDVLDVHWYPEARGGGERICFGADPRNIET 3IK2:A $241 / 242$ WSSVKGNY ONFIDYYLDNMKKNSDAAGKRLLDALDLHWY PEA KGGGQRVT-TSDTSNVDC

Figure 5 Phylogenetic tree created using the structure-based multiple sequence alignments in each fold. The thermophilic proteins are shown in boxes. The thermophilic-mesophilic protein pairs sharing a close evolutionary relationship that have been selected for further analysis are marked with black stars for each of the three folds: $(A)(\alpha / \beta)_{8,}$ (B) $\beta$-jelly roll, and (C) $(\alpha / \alpha)_{6}$. (D) A fragment of the pairwise alignment between the thermophilic (pdb id: 2e4t) and mesophilic (pdb id: 3ik2) $(\alpha / \beta)_{8}$ pair is shown to demonstrate the sequence differences for the statistically significant amino acid arginine in the thermophilic protein. Four arginine positions (shown in boxes) in the thermophilic protein are substituted by different amino acids in the mesophilic protein.

is statistically significant in mesophiles (Figure 2E, Figure 3 and Additional file 2). Glu and Val were not located in secondary structure and surface accessibility classes in a statistically significant manner (Figure 4, Additional file 3 and Additional file 4).
Among the three folds of endoglucanases, it is interesting to note that the individual amino acid frequencies do not follow a similar pattern. Each fold has specific groups of amino acids that are significant, which cannot be universally applied to other folds, highlighting the importance

Table 2 Pairwise structural alignment of evolutionarily related thermophilic and mesophilic protein pairs for $(\alpha / \beta)_{8}$, $\beta$-jelly roll, and $(\alpha / \alpha)_{6}$ folds

\begin{tabular}{|c|c|c|c|c|c|c|c|c|}
\hline \multirow[b]{2}{*}{ Fold } & \multirow[b]{2}{*}{ Thermophile } & \multirow[b]{2}{*}{ Mesophile } & \multirow[b]{2}{*}{ RMSD (Å) } & \multirow[b]{2}{*}{ Z-score } & \multicolumn{2}{|c|}{ Protein length } & \multirow[b]{2}{*}{$\begin{array}{c}\text { Sequence identity } \\
(\%)\end{array}$} & \multirow[b]{2}{*}{$\begin{array}{c}\text { Aligned/ } \\
\text { Gap }\end{array}$} \\
\hline & & & & & Thermophile & Mesophile & & \\
\hline$(\alpha / \beta)_{8}$ & $\begin{array}{l}\text { Clostridium } \\
\text { thermocellum } \\
\text { (pdb id: } 2 \mathrm{e} 4 \mathrm{t} \text { ) }\end{array}$ & $\begin{array}{c}\text { Clostridium } \\
\text { acetobutylicum } \\
\text { (pdb id: 3ik2) }\end{array}$ & 0.9 & 8.3 & 509 & 512 & 60.6 & $507 / 4$ \\
\hline $\begin{array}{l}\beta \text {-jelly } \\
\text { roll }\end{array}$ & $\begin{array}{l}\text { Rhodotermus marinus } \\
\text { (pdb id: } 2 \text { bw8) }\end{array}$ & $\begin{array}{l}\text { Streptomyces lividans } \\
\quad \text { (pdb id: } 2 \text { nlr) }\end{array}$ & 1.2 & 7.2 & 227 & 234 & 33.3 & $219 / 9$ \\
\hline$(\alpha / \alpha)_{6}$ & $\begin{array}{l}\text { Clostridium } \\
\text { thermocellum } \\
\text { (pdb id: } 111 \mathrm{y} \text { ) }\end{array}$ & $\begin{array}{l}\text { Clostridium } \\
\text { cellulolyticum } \\
\text { (pdb id: } 1 \mathrm{~g} 9 \mathrm{~g} \text { ) }\end{array}$ & 0.8 & 8.3 & 678 & 629 & 61.6 & $612 / 33$ \\
\hline
\end{tabular}




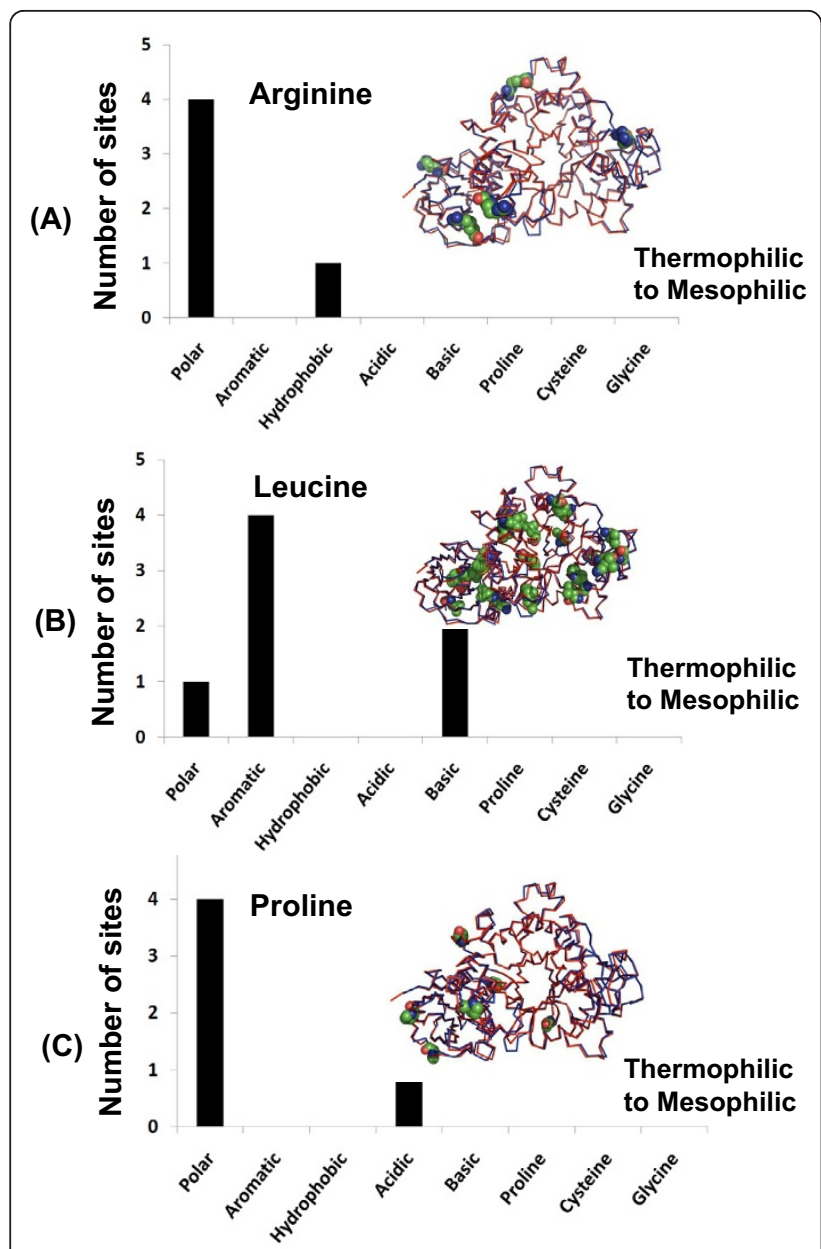

Figure 6 Mesophilic substitutions at the structurally equivalent positions of significant amino acid types in thermophiles for the $(\alpha / \beta)_{8}$ fold based on pairwise structural alignments. Statistically significant amino acid types are (A) arginine, (B) leucine, and $(C)$ proline. Structurally equivalent positions of aligned amino acids between mesophilic endoglucanases and their structurally similar thermophilic counterpart were analyzed for substitutions. The $x$-axis shows the type or class of amino acids substituted in mesophiles. The count of substitution sites is plotted as a histogram for the following pair shown in Figure 3A: Clostridium thermocellum $\left(\mathrm{C}^{\alpha}\right.$ trace colored in red, pdb id: 2e4t) and mesophile Clostridium acetobutylicum ( $C^{\alpha}$ trace colored in blue, pdb id: 3ik2). Positions of the amino acids are shown in CPK model in superimposed protein structures, where they are differentially colored with respect to atom type.

that sequence plays in determining structure. But also, and more importantly, this result indicates that amino acids responsible for thermophilicity may not rely on enzyme family but more specifically on the protein fold.

\section{Evolutionarily related thermophilic and mesophilic} protein pairs in endoglucanases

Multiple structural alignment of thermophilic and mesophilic proteins in each fold was performed to identify structurally and evolutionarily similar proteins. Phylogenetic trees were constructed using the structure-based multiple sequence alignments of each fold (Figure $5 \mathrm{a}$, $5 \mathrm{~b}$, and $5 \mathrm{c}$ ). From these trees, the closest pair of thermophilic and mesophilic proteins for each fold was identified and selected for further analysis of possible thermostabilizing differences. Table 2 lists these three pairs of thermophilic and mesophilic proteins: Clostridium thermocellum (pdb id: 2e4t) and Clostridium acetobutylicum (pdb id: 3ik2); Rhodotermus marinus (pdb id: 2bw8) and Streptomyces lividans (pdb id: 2nlr); and Clostridium thermocellum (pdb id: 111y) and Clostridium cellulolyticum (pdb id: $1 \mathrm{~g} 9 \mathrm{~g}$ ) from the $(\alpha / \beta)_{8}, \beta$ jelly roll, and $(\alpha / \alpha)_{6}$ folds respectively.

Structural superimposition for each of the three pairs shows the RMSD is below $1.5 \AA$ and Z-score above 7.2, indicating that the pairwise structural comparison is of a very good quality (Table 2 ). According to $C E$ algorithm, a Z-score of above 3.5 indicates a very high statistical significance of structural alignment, which can also be seen by the very low number of gaps in each of the alignment (Table 2).

Using pairwise structural alignments for each of these three sets, we were able to identify all the positions where the statistically significant amino acids differ and tally the nature of these substitutions. In particular, each substitution was counted as being polar, aromatic, hydrophobic, acidic, basic, proline, cysteine, or glycine. Figures 6, 7, 8 plot the results for each significant amino acid from each fold. Proline and glycine substitutions were separately counted because the presence of these two amino acids disrupts secondary structure by helixbreaking (Pro) and high flexibility (Gly). Likewise, Cys substitutions were counted separately because of their ability to form disulfide bonds.

For the $(\alpha / \beta)_{8}$ fold (Figure 6), Arg and Pro (significant in thermophiles) are overwhelmingly replaced by polar amino acids whereas Leu is primarily replaced with aromatic amino acids in the mesophilic counterpart. The replacement of arginines by non-basic polar amino acids in mesophiles supports the view that increased arginine content enhances thermostability. Conversely, the absence of these arginine amino acids leads to a loss of ionic interactions in mesophiles, rendering them enzymatically inactive at higher temperatures.

In the $\beta$-jelly roll fold (Figure 7), the amino acids Glu, Arg, and His are substituted with polar, hydrophobic amino acids. Substitution to Pro is higher for Arg indicating the potential for fewer salt-bridges in mesophiles. Quantitatively, we observe only 4 to 11 salt bridges in the mesophiles versus 16 to 40 salt bridges in the thermophiles for this fold. It is unclear as to how the mesophilic protein benefits from substitution of positively charged amino acids with negatively charged amino 


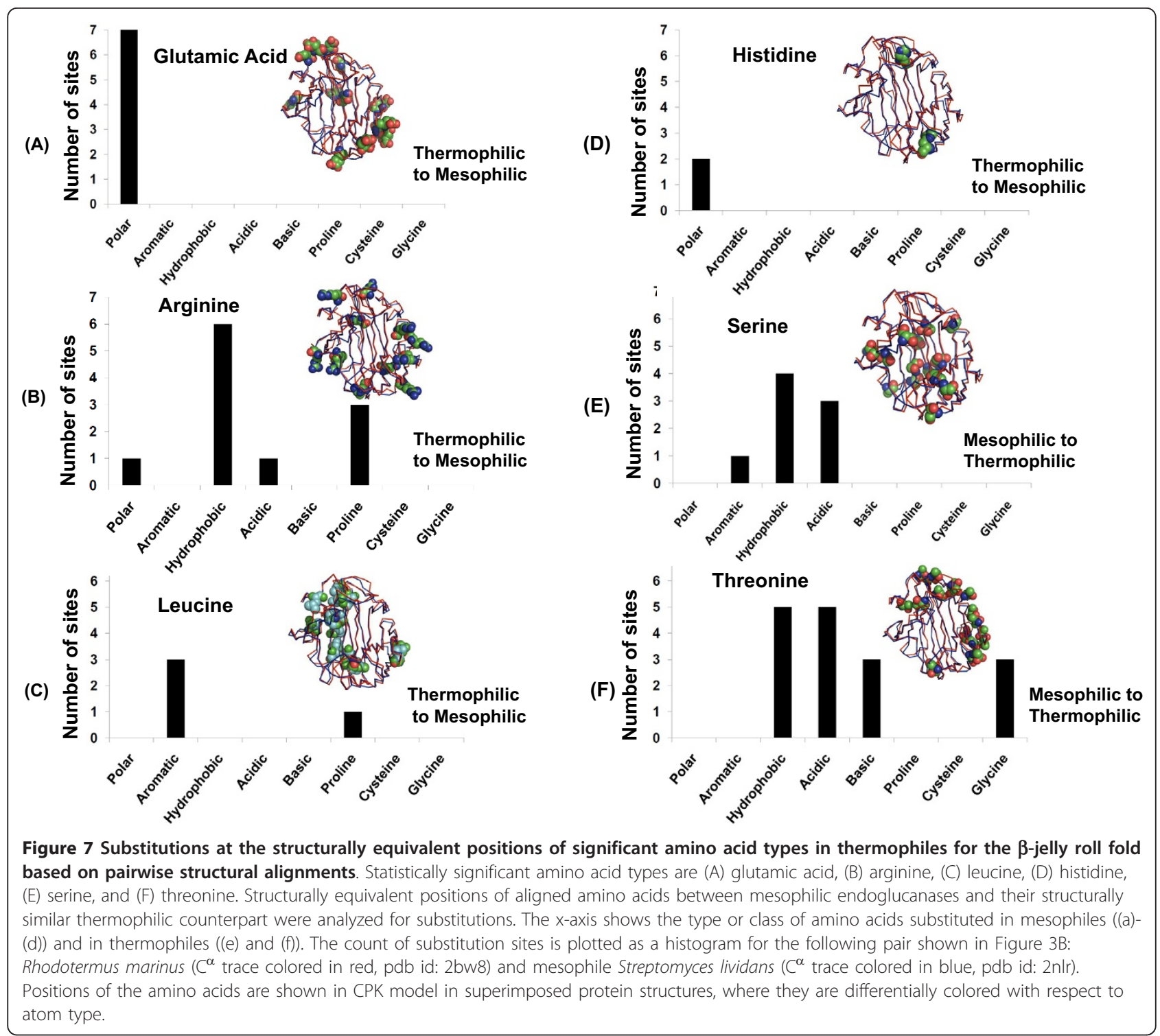

acids. It is however possible that because some thermophiles lived in acidic environments during their evolutionary history (as some still do), they might have a preference for positively charged amino acids that is carried over the generations that mesophiles do not have a need for. For the Ser and Thr positions (significant among mesophiles) the thermophilic protein has hydrophobic, acidic, and basic amino acids substituted. Interestingly, Thr is substituted with Gly in the thermophilic protein at some positions.

In the $(\alpha / \alpha)_{6}$ fold (Figure 8), Glu and Val are replaced with polar amino acids and to a lesser extent with other amino acid groups. Gln (significant in mesophiles) is substituted to a large extent by hydrophobic, acidic and to a lesser extent with basic amino acid groups in thermophiles indicating that in the thermophilic protein these substitutions contribute towards more intramolecular interactions and extend stability to proteins at higher temperatures such as has been suggested previously as inducing better hydrophobic cores and packing [8].

\section{Comparison to previous family-level and proteome-level studies}

Comparing our results to the previously reported thermophilic-mesophilic comparative studies, we find that observations made for analysis across diverse families of proteins do not necessarily correspond with our familyspecific analysis.

For example, Chakravarty and Varadarajan had reported [16] that $\mathrm{Val}$ and Glu were significantly higher in thermophiles, which matches only to $(\alpha / \alpha)_{6}$ fold. Also, we find that Glu is significant only in $\beta$-jelly roll 


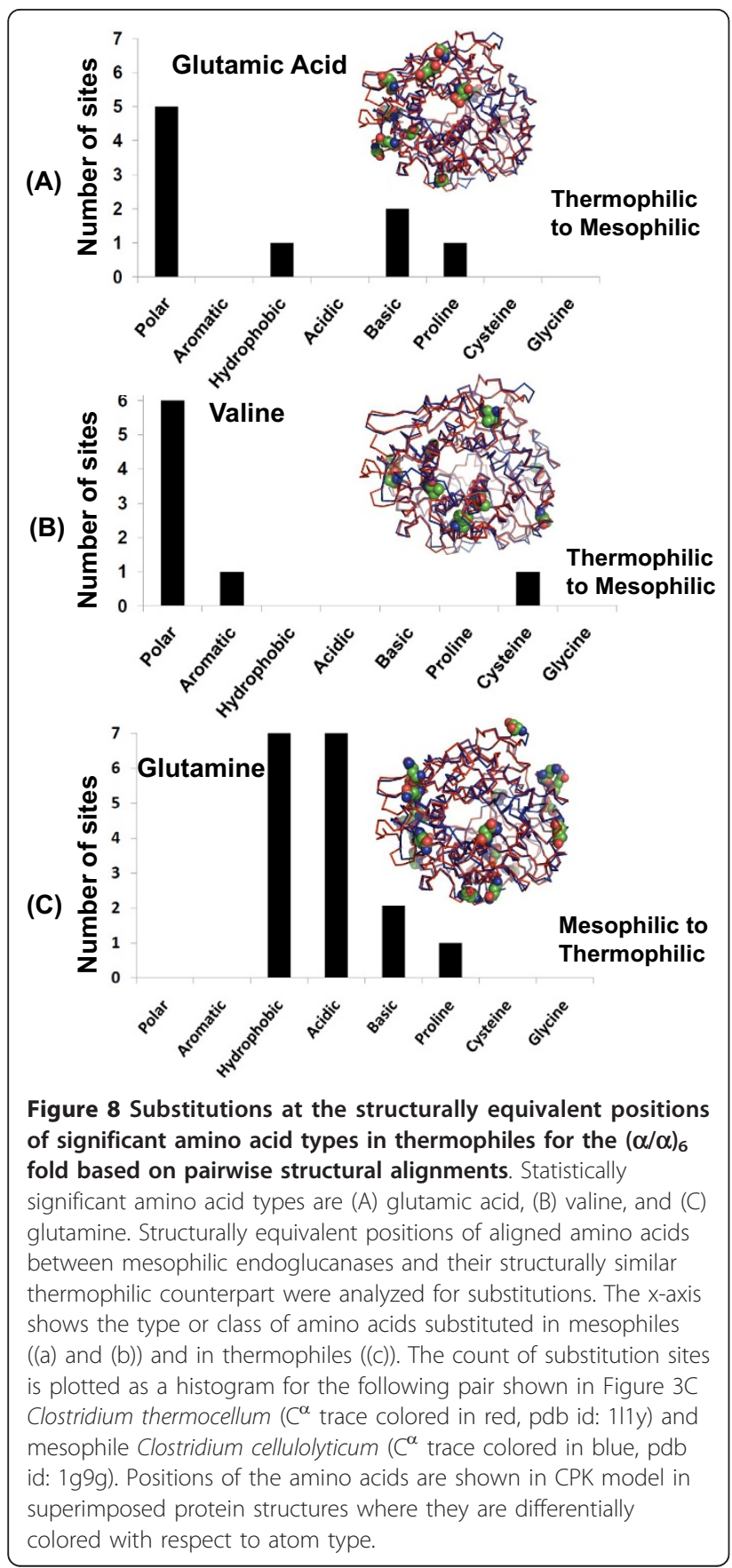

fold and not in the $(\alpha / \beta)_{8}$ fold. At the same time, we observe that Gln, Ser, and Thr are significant in mesophiles which is in agreement to their results. However, when it comes to surface accessibility, we do not find any of the significant amino acids in thermophiles as exposed (Figure 4) in the three folds, whereas Chakravarty and Varadarajan found that the significant amino acids in thermophiles are significantly exposed to the surface.
Kumar et al performed a detailed statistical analysis for non-redundant dataset of 18 families [7]. A pair of thermophilic and mesophilic with high structural similarity from each family was selected. Among the amino acids, Arg and Tyr were found to be significantly higher in thermophiles. Among the intramolecular interactions, salt bridges, SC-SC hydrogen bonds were significantly higher in thermophiles.

Comparing our results to Berezovsky et al [15] we also find positively charged amino acids significantly higher in thermophiles, specifically Arg and His. However, we did not find another positively charged amino acid, Lys, significant in thermophiles. Also, since our study involved single-domain proteins we did not calculate as to how the protein interface is stabilized in thermophilic proteins.

Our results also agree with Berezovsky and Shakhnovich's [5] observation about sequence dependent strong interactions for thermostability. However, we see that only the $\beta$-jelly roll fold has (MC-MC, Ionic, and Cation- $\pi$ ) significant interactions in thermophiles.

\section{Conclusions}

Understanding the processes responsible for thermostability in endoglucanases is complicated by the large range of structural and sequence diversity these enzymes adopt. Previous studies to derive trends explaining thermostability have focused on large number of protein families, but not necessarily on distinct folds of the same enzyme. In this study we have analyzed the known endoglucanase structures from the PDB and have shown that protein folds rather than protein families are more important when defining rules for thermophilicity. Previous studies [5,7] used the presence or absence of certain types of amino acids in secondary structures (helix, sheet, and loop) as an indication of their role in thermostability. We observed a similar pattern for endoglucanases, as shown in Figure 3, but the types of amino acids contributing to thermostability for the three specific folds studied here differ from those obtained using a more diverse set of proteins. Comparisons between evolutionarily close pairs of thermophilic and mesophilic endoglucanases in each of the fold, reinforces previous assertions that charged amino acids (Arg, His, and Glu) are important for stabilizing the protein at higher temperatures. But one should note that the solvent accessibility of these amino acids also plays a role.

When it comes to thermostability, there is a caveat of applying general heuristic rules based on averaged properties to specific proteins: although thermostability in endoglucanases is usually conferred through altering amino acid composition, in some cases even a singlepoint mutation is sufficient to convert a mesophilic protein into a thermophilic protein [14]. 
Upon analyzing the amino acid compositions and intramolecular interactions for the three folds adopted by endoglucanases a paradoxical picture emerges. Namely, although some amino acids are far more significant in thermophiles or mesophiles, they may not significantly alter the overall intramolecular interactions. For example, in the $(\alpha / \beta)_{8}$ fold, Arg is statistically significant, but ionic interactions are not statistically significant within this fold. Similarly in the $\beta$-jelly roll fold, Cys is statistically significant, but the disulfide bridges are not significant. We see a similar pattern for the $(\alpha / \alpha)_{6}$ fold where although Glu is statistically significant, none of the intramolecular interactions are. These results suggest that subtle changes in interactions act as driving factors for thermostability.

For thermophilic proteins, distinct folds have distinct factors that contribute to thermostability, suggesting a fold-specific protein analysis requirement to understand thermostability. Understanding the basis for thermostability aids in engineering enhanced protein activity, which can lead to more cost effective processes for many industrial applications. Our study sheds light on endoglucanases, which could possibly be exploited to increase biofuels crop production by designing a more efficient endoglucanase enzyme. The enzymes currently used in converting biomass to bioethanol for biofuel production have been derived from microorganisms. Unfortunately there are serious technological limitations on biofuel production due to low yield and high production costs for pre-processing enzymes like endoglucanases. Thus the ability to insert a more efficiently designed thermophilic endoglucanase into maize would be very exciting [1].

\section{Methods}

\section{Protein Dataset}

A dataset of endoglucanase protein structures was obtained from the more than 100 glycoside hydrolase $(\mathrm{GH})$ families within the Carbohydrate-Active enZymes database (CAZy) [38]. The enzyme classification number 3.2.1.4 was used to identify all endoglucanases from these various $\mathrm{GH}$ families and group them based upon their three-dimensional structural fold. Endoglucanase structures determined by either X-ray crystallography or NMR spectroscopy were classified into one of three structural folds: $(\alpha / \beta)_{8}, \beta$-jelly roll, or $(\alpha / \alpha)_{6}$. Using the primary citation of the PDB structure for conformation, each protein was identified as either thermophilic and mesophilic in the following manner: if the source organism's optimum growth temperature $\left(\mathrm{T}_{\mathrm{L}}\right)$ is above $40^{\circ} \mathrm{C}$, then the protein was classified as thermophilic; if not, as mesophilic. We note that although the melting temperature $\left(\mathrm{T}_{\mathrm{m}}\right)$ of a given protein is a better indicator of its thermostability than growth temperature of the organism, the melting temperature is not often widely available. For instance we sought $\mathrm{T}_{\mathrm{m}}$ values for all the proteins in our dataset from the ProTherm database [39], but except for one thermophilic protein (pdb id: 1olr) and for one mesophilic protein (pdb id: 1oa2) the $\mathrm{T}_{\mathrm{m}}$ values are unavailable. Previous studies comparing thermophilic and mesophilic proteins also have mentioned that unavailability of $\mathrm{T}_{\mathrm{m}}$ values is a limiting factor [7]. Since we are only using this information to broadly classify proteins as thermophilic or mesophilic rather than define a direct correlation with $T_{m}$, we follow the precedent of classifying by $\mathrm{T}_{\mathrm{L}}$ [7].

To ensure a similar degree of sequence variation within each of these protein subsets, proteins with greater than $70 \%$ sequence and structural similarity were removed using PISCES [40]. For a given set of PDB entries, PISCES uses Combinatorial Extension (CE) algorithm and PSI-BLAST alignments to create a subset of proteins that are evolutionarily related, but with low sequence identity. Our final datasets, listed in Table 1, contained 17 thermophiles and 13 mesophiles.

\section{Comparisons of sequence and structure based features}

Following the results of previous thermophilic-mesophilic comparison studies $[7,8]$, we calculated the statistical significance for several potentially stabilizing features derived from endoglucanase sequences and structures. Statistical significance was defined as having a p-value less than $5.0 \times 10^{-2}$ (95\% confidence interval) in an unpaired two-tail t-test using the statistical software $\mathrm{R}$ [41] between differences in mesophilic and thermophilic proteins. All the structures in Table 1 are divided into thermophilic and mesophilic structure sets. The amino acid frequency for each type of amino acid was calculated for each protein. These amino acid frequencies were averaged within the family and used as input into the t-tests to determine which, if any, amino acids displayed a statistically significant difference. When an amino acid was observed to be statistically significant, $(\mathrm{p}<0.05)$ then the set, thermophilic or mesophilic, that had a higher mean frequency was determined to be significantly richer in that amino acid. These tests were repeated for three different groupings of thermophilic and mesophilic sets: all endoglucanases, split by their catalytic mechanism, split by their fold. Additional features based upon intramolecular interactions and relative amino acid environment were compared in similar ways.

DSSP [42] was used to determine the secondary structure of proteins. We used the following scheme to translate eight-letter DSSP code into a three-class scheme where secondary structure states of $\alpha$ helix $(H), 3-10$ helix (G), and $\pi$ helix (I) are translated into helix; isolated $\beta$-bridge (B) and extended strand (E) are translated 
into sheet; and hydrogen bonded turn (T) and bend (S) are translated into loop. We also used DSSP to obtain a measure of relative solvent accessibility, $A_{i}$, for each residue, $i$. Equation 1 describes how the relative solvent accessibility is calculated.

$$
A_{i}=\frac{(\text { DSSP solvent accessibility })_{i}}{\text { Maximum accessibility for residue of type } i}
$$

As suggested previously, this relative solvent accessibility, $A_{i}$, was classified as: (1) buried if less than $9 \%,(2)$ intermediate if between 9-36\% and (3) exposed if more than $36 \%$ [43]. Another t-test was used to identify statistically significance differences between mesophilic and thermophilic endoglucanases for any amino acids with these various accessibility states. In these tests, the count of each type of amino acid participating in an accessibility state or secondary structure class was normalized by the total number of that particular amino acid type in each protein.

Finally the Protein Interaction Calculator (PIC) [44] was used to calculate the intramolecular interactions, such as hydrophobic interactions; hydrogen bond interactions (main chain-main chain (MC-MC), main chainside chain (MC-SC), and side chain-side chain (SC-SC)); disulphide bridges; ionic interactions (distance cutoff of 6̊) [45]; aromatic-aromatic interactions (distance cutoff of $4.5 \AA$ to $7 \AA$ ) [46]; aromatic-sulfur interactions

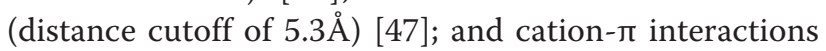
(distance cutoff of $6 \AA$ ) [48]. For statistical analysis, the number of interactions in each category was normalized by the number of residues in each protein.

\section{Phylogenetic analysis of thermophilic and mesophilic proteins}

In order to identify similar regions in evolutionary related thermophiles and mesophiles, we structurally aligned proteins using the multiple structure alignment tool CE [49]. To check the accuracy of alignments we analyzed if the catalytic residues were aligned among the thermophiles and mesophiles. The results were visualized using PyMol [50]. With this simple check for alignment performance, we used the PHYlogeny Inference Package (PHYLIP) [51] to construct a phylogenetic tree of endoglucanases. The structure based multiple sequence alignments were given as input to PHYLIP and distances were calculated using maximum likelihood estimates based on the Jones-Taylor-Thornton matrix [52]. Then, a neighbor-joining method was used to cluster the sequences using the distance matrix. Based on the clustered phylogenetic tree, we identified at least one pair of thermophilic and mesophilic proteins for each fold, that are structurally similar and evolutionarily related.

\section{Additional material}

Additional file 1: Intramolecular interactions count for the three
folds.
Additional file 2: Results of unpaired t-test.
Additional file 3: Count of statistically significant amino acids.
Additional file 4: Results of unpaired t-test, showing the p-value of
statistically significant amino acids (bold and underlined) for secondary
structure and relative surface accessibility preferences in thermophiles.

\section{Acknowledgements}

We would like to thank the anonymous reviewers for their highly appreciated comments. This project is supported by the Biotechnology Risk Assessment Program Competitive Grant no. 2008-33522-04758 from the USDA National Institute of Food and Agriculture and USDA-Agricultural Research Service.

\section{Author details}

'Department of Genetics, Development and Cell Biology, lowa State University, Ames, IA 50011, USA. ²Department of Physics, Indiana UniversityPurdue University Indianapolis, Indianapolis, IN 46202, USA. ${ }^{3}$ Biosafety Institute for Genetically Modified Agricultural Products and Department of Agronomy, lowa State University, Ames, IA 50011, USA. ${ }^{4}$ U.S. Department of Agriculture - Agricultural Research Service, Corn Insects and Crop Genomics Research Unit, Ames, IA, 50011, USA. ${ }^{5}$ Bioinformatics and Computational Biology Program, lowa State University, Ames, IA, 50011, USA.

\section{Authors' contributions}

TZS and JDW conceived the study and participated in its design and coordination and helped to draft the manuscript. RMY conducted the studies and drafted the manuscript. AJR gave valuable suggestions and finalized the manuscript. All authors read and approved the final manuscript.

Received: 3 June 2010 Accepted: 3 February 2011

Published: 3 February 2011

\section{References}

1. Ransom C, Balan V, Biswas G, Dale B, Crockett E, Sticklen M: Heterologous Acidothermus cellulolyticus $1,4-\beta$-endoglucanase E1 produced within the corn biomass converts corn stover into glucose. Applied Biochemistry and Biotechnology 2007, 137-140:207-219.

2. Wood TM, McCrae SI: The cellulase of Trichoderma koningii. Purification and properties of some endoglucanase components with special reference to their action on cellulose when acting alone and in synergism with the cellobiohydrolase. Biochem J 1978, 171:61-72.

3. Valjamae P, Sild V, Nutt A, Pettersson G, Johansson G: Acid hydrolysis of bacterial cellulose reveals different modes of synergistic action between cellobiohydrolase I and endoglucanase I. Eur J Biochem 1999, 266:327-334.

4. Hilden L, Johansson G: Recent developments on cellulases and carbohydrate-binding modules with cellulose affinity. Biotechnol Lett 2004, 26:1683-1693.

5. Berezovsky IN, Shakhnovich El: Physics and evolution of thermophilic adaptation. Proc Natl Acad Sci USA 2005, 102:12742-12747.

6. Hsiang-Chuan L: A Novel Prediction Algorithm of Thermostable Proteins by Using Hurst Exponent and Choquet Integral Regression Model.Edited by: Yu-Chieh T, Bai-Cheng J, Tung-Sheng L 2008, 147-152.

7. Kumar S, Tsai CJ, Nussinov R: Factors enhancing protein thermostability. Protein Eng 2000, 13:179-191.

8. Sadeghi M, Naderi-Manesh H, Zarrabi M, Ranjbar B: Effective factors in thermostability of thermophilic proteins. Biophys Chem 2006, 119:256-270.

9. Razvi A, Scholtz JM: Lessons in stability from thermophilic proteins. Protein Sci 2006, 15:1569-1578.

10. Glyakina AV, Garbuzynskiy SO, Lobanov MY, Galzitskaya OV: Different packing of external residues can explain differences in the thermostability of proteins from thermophilic and mesophilic organisms. Bioinformatics 2007, 23:2231-2238. 
11. Gromiha MM, Oobatake M, Sarai A: Important amino acid properties for enhanced thermostability from mesophilic to thermophilic proteins. Biophys Chem 1999, 82:51-67.

12. Panasik N, Brenchley JE, Farber GK: Distributions of structural features contributing to thermostability in mesophilic and thermophilic alpha/ beta barrel glycosyl hydrolases. Biochim Biophys Acta 2000, 1543:189-201.

13. Sonia M De Freitas, Werner L Treptow, Fabricia P De Faria, Maristela De O Azevedo, Maigret B: Structural Contributions for Thermostability of a New Endo-1,4-beta-xylanase from the Fungus Humicola grisea. Internet Electronic Journal of Molecular Design 2003, 2:835-851.

14. Sandgren M, Gualfetti PJ, Shaw A, Gross LS, Saldajeno M, Day AG, Jones TA, Mitchinson C: Comparison of family 12 glycoside hydrolases and recruited substitutions important for thermal stability. Protein Sci 2003, 12:848-860.

15. Ma BG, Goncearenco A, Berezovsky IN: Thermophilic adaptation of protein complexes inferred from proteomic homology modeling. Structure 2010, 18:819-828.

16. Chakravarty $S$, Varadarajan R: Elucidation of factors responsible for enhanced thermal stability of proteins: a structural genomics based study. Biochemistry 2002, 41:8152-8161.

17. Bell GS, Russell RJ, Connaris H, Hough DW, Danson MJ, Taylor GL: Stepwise adaptations of citrate synthase to survival at life's extremes. From psychrophile to hyperthermophile. Eur J Biochem 2002, 269:6250-6260.

18. Arnold FH, Giver L, Gershenson A, Zhao H, Miyazaki K: Directed evolution of mesophilic enzymes into their thermophilic counterparts. Ann N Y Acad Sci 1999, 870:400-403.

19. Perl D, Mueller U, Heinemann U, Schmid FX: Two exposed amino acid residues confer thermostability on a cold shock protein. Nat Struct Mol Biol 2000, 7:380-383.

20. Uversky $\mathrm{VN}$ : Intrinsically disordered proteins and their environment: effects of strong denaturants, temperature, $\mathrm{pH}$, counter ions, membranes, binding partners, osmolytes, and macromolecular crowding. Protein J 2009, 28:305-325.

21. Kumar N, Shukla S, Kumar S, Suryawanshi A, Chaudhry U, Ramachandran S, Maiti S: Intrinsically disordered protein from a pathogenic mesophile Mycobacterium tuberculosis adopts structured conformation at high temperature. Proteins: Structure, Function, and Bioinformatics 2008, 71:1123-1133.

22. Tantos A, Friedrich P, Tompa P: Cold stability of intrinsically disordered proteins. FEBS Lett 2009, 583:465-469.

23. Stebbins CE, Galan JE: Structural mimicry in bacterial virulence. Nature 2001, 412:701-705

24. Sharon N, Lis $\mathrm{H}$ : How proteins bind carbohydrates: lessons from legume lectins. J Agric Food Chem 2002, 50:6586-6591.

25. Aminetzach YT, Srouji JR, Kong CY, Hoekstra HE: Convergent Evolution of Novel Protein Function in Shrew and Lizard Venom. Current Biology 2009, 19:1925-1931.

26. Barten R, Torkar M, Haude A, Trowsdale J, Wilson MJ: Divergent and convergent evolution of NK-cell receptors. Trends Immunol 2001, 22:52-57.

27. Bork P, Sander C, Valencia A: Convergent evolution of similar enzymatic function on different protein folds: The hexokinase, ribokinase, and galactokinase families of sugar kinases. Protein Science 1993, 2:31-40.

28. Henrissat B, Bairoch A: Updating the sequence-based classification of glycosyl hydrolases. Biochem J 1996, 316(Pt 2):695-696.

29. Sandgren M, Stahlberg J, Mitchinson C: Structural and biochemical studies of GH family 12 cellulases: improved thermal stability, and ligand complexes. Prog Biophys Mol Biol 2005, 89:246-291.

30. Oraby H, Venkatesh B, Dale B, Ahmad R, Ransom C, Oehmke J, Sticklen M: Enhanced conversion of plant biomass into glucose using transgenic rice-produced endoglucanase for cellulosic ethanol. Transgenic Res 2007, 16:739-749.

31. Lopez-Casado G, Urbanowicz BR, Damasceno CM, Rose JK: Plant glycosyl hydrolases and biofuels: a natural marriage. Curr Opin Plant Biol 2008, 11:329-337.

32. Wierenga RK: The TIM-barrel fold: a versatile framework for efficient enzymes. FEBS Lett 2001, 492:193-198.

33. Alzari PM, Souchon $H$, Dominguez R: The crystal structure of endoglucanase CelA, a family 8 glycosyl hydrolase from Clostridium thermocellum. Structure 1996, 4:265-275.

34. Guimaraes BG, Souchon H, Lytle BL, David Wu JH, Alzari PM: The crystal structure and catalytic mechanism of cellobiohydrolase CelS, the major enzymatic component of the Clostridium thermocellum Cellulosome. J Mol Biol 2002, 320:587-596.

35. Guerin DM, Lascombe MB, Costabel M, Souchon H, Lamzin V, Beguin P, Alzari PM: Atomic (0.94 A) resolution structure of an inverting glycosidase in complex with substrate. J Mol Biol 2002, 316:1061-1069.

36. Vogt G, Woell S, Argos P: Protein thermal stability, hydrogen bonds, and ion pairs. J Mol Biol 1997, 269:631-643.

37. Beeby M, O'Connor BD, Ryttersgaard C, Boutz DR, Perry LJ, Yeates TO: The genomics of disulfide bonding and protein stabilization in thermophiles. PLOS Biol 2005, 3:e309.

38. Cantarel BL, Coutinho PM, Rancurel C, Bernard T, Lombard V, Henrissat B: The Carbohydrate-Active EnZymes database (CAZy): an expert resource for Glycogenomics. Nucleic Acids Res 2009, 37:D233-238.

39. Kumar MD, Bava KA, Gromiha MM, Prabakaran P, Kitajima K, Uedaira H, Sarai A: ProTherm and ProNIT: thermodynamic databases for proteins and protein-nucleic acid interactions. Nucleic Acids Res 2006, 34:D204-206.

40. Wang G, Dunbrack RL, Jr : PISCES: a protein sequence culling server. Bioinformatics 2003, 19:1589-1591.

41. R-Development-Core-Team: R: A Language and Environment for Statistical Computing Vienna, Austria: R Foundation for Statistical Computing; 2008

42. Kabsch W, Sander C: Dictionary of protein secondary structure: pattern recognition of hydrogen-bonded and geometrical features. Biopolymers 1983, 22:2577-2637.

43. Rost B, Sander C: Conservation and prediction of solvent accessibility in protein families. Proteins 1994, 20:216-226.

44. Tina KG, Bhadra R, Srinivasan N: PIC: Protein Interactions Calculator. Nucleic Acids Res 2007, 35:W473-476.

45. Barlow DJ, Thornton JM: lon-pairs in proteins. J Mol Biol 1983, 168:867-885.

46. Burley SK, Petsko GA: Aromatic-aromatic interaction: a mechanism of protein structure stabilization. Science 1985, 229:23-28.

47. Reid KSC, Lindley PF, Thornton JM: Sulphur-aromatic interactions in proteins. FEBS Letters 1985, 190:209-213.

48. Sathyapriya $R$, Vishveshwara S: Interaction of DNA with clusters of amino acids in proteins. Nucleic Acids Res 2004, 32:4109-4118.

49. Shindyalov IN, Bourne PE: Protein structure alignment by incremental combinatorial extension (CE) of the optimal path. Protein Eng 1998, 11:739-747.

50. DeLano WL: The PyMOL User's Manual. Book The PyMOL User's Manual City: DeLano Scientific, Palo Alto, CA, USA; 2002, (Editor ed.^eds.).

51. Felsenstein J: PHYLIP-Phylogeny Inference Package (Version 3.2). Cladistics 1989, 5:164-166.

52. Jones DT, Taylor WR, Thornton JM: The rapid generation of mutation data matrices from protein sequences. Comput Appl Biosci 1992, 8:275-282.

doi:10.1186/1472-6807-11-10

Cite this article as: Yennamalli et al:: Thermostability in endoglucanases is fold-specific. BMC Structural Biology 2011 11:10.

\section{Submit your next manuscript to BioMed Central and take full advantage of:}

- Convenient online submission

- Thorough peer review

- No space constraints or color figure charges

- Immediate publication on acceptance

- Inclusion in PubMed, CAS, Scopus and Google Scholar

- Research which is freely available for redistribution 